\title{
Heat transfer optimization in a fluidized bed biomass gasification reactor
}

\author{
R. K. Thapa \& B. M. Halvorsen \\ Department of Process, Energy and Environmental Technology, \\ Telemark University College, Norway
}

\begin{abstract}
A Computational Particle Fluid Dynamic (CPFD) model has been developed for the heat transfer optimization in a fluidized bed biomass gasification reactor with gasification reaction kinetics. The parameters investigated were bed material circulation rate, bed material inlet and outlet temperature, steam feed temperature and fluidizing velocity of steam. A series of simulations were performed for each of the parameters. Commercial CPFD software Barracuda was used for the simulations. The result of the simulations are used to propose optimal parameters for heat supply in the gasification reactor.

Keywords: heat transfer, fluidized bed reactors, CPFD, Eulerian-Lagrangian approach, reaction kinetics, biomass gasification.
\end{abstract}

\section{Introduction}

Biomass is the oldest source of energy known to the world. The renewable source of energy is neutral to $\mathrm{CO}_{2}$ and has less emission of sulphur and nitrogen compounds in comparison to fossil fuel [1]. In conventional power plants, biomass is combusted to produce steam. The steam is then used in steam cycle for power production. The overall efficiencies of those power plants are relatively low compared to the plants based on gasification of biomass. During the past two decades many research studies have been focused on the gasification of biomass. The technology allows producing a mixture of combustible gases instead of burning it directly to produce heat. The mixture of combustible gases can be used in gas turbines or engines to produce electric power and heat. The gas can also be further processed for the production of liquid and gaseous biofuels [2]. 
There are various types of technology for biomass gasification. One of them is a dual circulating fluidized bed gasification system. The technology was developed by Vienna University of Technology [3,4]. The fundamental principal of the gasification process is shown in Figure 1. The dual fluidized bed gasification system can be divided into two parts: gasification reactor and combustion reactor. The gasification part is a bubbling fluidized bed reactor where bed materials such as sand or olivine are fluidized by high temperature steam. Biomass feed to the reactor is mixed with the bed material and the steam. The biomass undergoes an endothermic gasification reaction to produce a mixture of combustible $\left(\mathrm{CO}, \mathrm{CH}_{4}, \mathrm{H}_{2}\right)$ and non-combustible $\left(\mathrm{CO}_{2}\right.$ and $\left.\mathrm{H}_{2} \mathrm{O}\right)$ gases. The heat required for the endothermic gasification reaction is supplied by fluidizing steam and the hot bed material supplied to the reactor from the combustion part of the system.

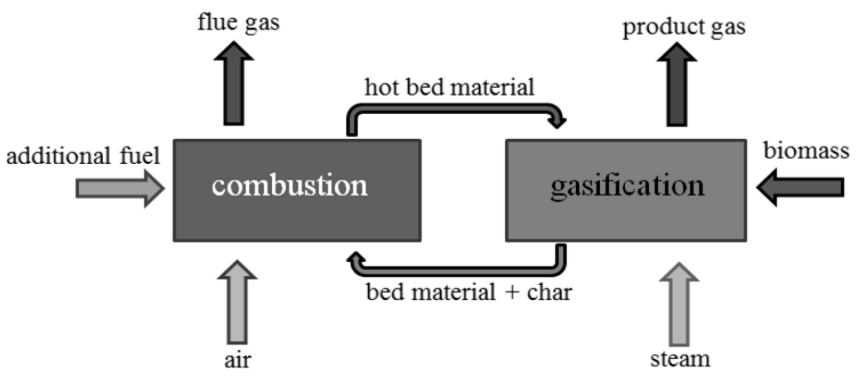

Figure 1: Principal of dual fluidized bed gasification process.

The combustion part is a circulating fluidized bed which is fluidized by ambient air. The purpose of the combustion reactor is to heat inert bed material. The heated bed material is circulated to the gasification reactor $[5,6]$.

The product gas quality and quantity depends on the endothermic gasification reaction occurring in the reactor. The endothermic reaction is dependent on the uniform and optimized heat transfer to the reactor. There is a great importance of heat transfer optimization in order to insure effective and efficient performance of fluidized bed gasification reactor. The optimization depends on factors as bed material circulation, steam feed rates and feed temperatures.

\section{Computational model}

A three dimensional computational model for dual fluidized bed gasification system has been developed. The model calculates gas-solid reacting flow and heat transfer using commercial Computational Particle Fluid Dynamic (CPFD) software Barracuda VR. 15. The details of the CPFD modelling approach can be found in publications $[7,8]$. In the model, the combustion part is replaced by inlet and outlet of the hot bed material as boundary conditions. The computational model of the reactor is shown in Figure 2. 
Heat supply to the reactor is accomplished through the boundaries of bottom steam and bed material inlet. Heat transfer to the reactor should ensure sufficient heat necessary for the endothermic gasification reaction. Excess heat reduces the performance of the reactor. Moreover, the heat transfer should be uniform in order to have a uniform gas composition and high quality product gas for the further use. The optimization of the heat transfer has the objective of finding the best thermo-chemical and fluid dynamic parameters in order to maintain uniform and appropriate heat supply for endothermic gasification reaction in the reactor.

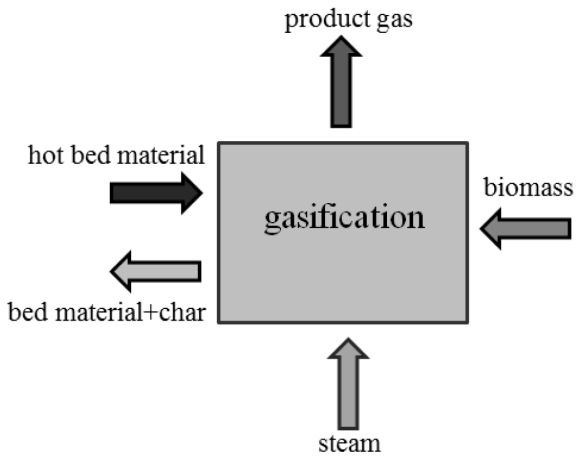

Figure 2: Computational model of the reactor.

The model considers analysis of the energy balance in the reactor. Energy is entered to the reactor in the form of biomass, hot bed material and bottom steam. Energy outlet from the reactor is in the form of a mixture of bed material with some unreacted char particles leaving at the dense bed and product gas leaving at the top of the reactor. The optimization of heat transfer should ensure maximum energy outlet in the form of product gas and minimizing the energy outlet in the form of bed material with char particles. The objective is to find the optimum fluid dynamic and thermo-chemical parameters which insure maximum conversion of input energy to the energy of product gas.

The energy of the product gas constitutes the sum of heating values of combustible gases, enthalpy of formation and sensible enthalpy of all component of product gas. The term 'total product gas energy' is further used to indicate the sum of energy

The energy conversion in the form of product gas, the composition and flow rates are analysed using the gasification reaction and the kinetics presented in Table 1 [9-11].

The thermo-chemical and fluid dynamic parameters studied are bed material circulation rate, bed material feed temperature, steam feed rate and steam feed temperature. Energy conversion and product gas composition as a function of these parameters need to be analysed in order to optimize them. Some of the constant parameters used in the model are given in Table 2. 
Table 1: Reaction kinetics used in the simulations.

\begin{tabular}{|c|c|}
\hline Reactions & Reaction kinetics \\
\hline $\begin{array}{l}\text { Steam gasification } \\
\mathrm{C}+\mathrm{H}_{2} \mathrm{O}=\mathrm{H}_{2}+\mathrm{CO}\end{array}$ & $r_{1}=2.7 \times 10^{7} m_{s} P^{0.73} \theta_{f} \exp \left(\frac{-26506}{T}\right)\left[H_{2} O\right]$ \\
\hline $\begin{array}{l}\text { Carbon-dioxide } \\
\text { gasification } \\
\mathrm{C}+\mathrm{CO}_{2}=2 \mathrm{CO}\end{array}$ & $r_{2}=1.12 \times 10^{8} m_{s} P^{0.31} \theta_{f} \exp \left(\frac{-29518}{T}\right)\left[C O_{2}\right]$ \\
\hline $\begin{array}{c}\text { Methanation } \\
0.5 \mathrm{C}+\mathrm{H}_{2}=0.5 \mathrm{CH}_{4}\end{array}$ & $r_{3}=1.368 \times 10^{-3} m_{s} T \exp \left(\frac{-8078}{T}-7.087\right)\left[H_{2}\right]$ \\
\hline $\begin{array}{l}\text { Water- gas shift reaction } \\
\mathrm{CO}+\mathrm{H}_{2} \mathrm{O}=\mathrm{CO}_{2}+\mathrm{H}_{2}\end{array}$ & $r_{4}=7.68 \times 10^{10} m_{s} T \exp \left(\frac{-36640}{T}\right)[\mathrm{CO}]^{0.5}\left[\mathrm{H}_{2} \mathrm{O}\right]$ \\
\hline $\begin{array}{c}\text { Methane reforming } \\
\mathrm{CH}_{4}+\mathrm{H}_{2} \mathrm{O}=\mathrm{CO}+3 \mathrm{H}_{2}\end{array}$ & $r_{5}=3.0 \times 10^{5} T \exp \left(\frac{-15042}{T}\right)\left[\mathrm{CH}_{4}\right]\left[\mathrm{H}_{2} \mathrm{O}\right]$ \\
\hline
\end{tabular}

Table 2: Some constant parameters used in the model.

\begin{tabular}{|l|c|c|l|c|c|}
\hline Parameter & Unit & Value & Parameter & Unit & Value \\
\hline $\begin{array}{l}\text { Biomass inlet } \\
\text { temperature }\end{array}$ & $\mathrm{K}$ & 300 & Biomass feed rate & $\mathrm{kg} / \mathrm{s}$ & 0.125 \\
\hline $\begin{array}{l}\text { Reactor } \\
\text { diameter }\end{array}$ & $\mathrm{m}$ & 0.55 & Reactor height & $\mathrm{m}$ & 2.00 \\
\hline $\begin{array}{l}\text { Initial bed } \\
\text { height }\end{array}$ & $\mathrm{m}$ & 0.25 & $\begin{array}{l}\text { Wood feed } \\
\text { position from the } \\
\text { bottom of the } \\
\text { reactor }\end{array}$ & $\mathrm{m}$ & 0.15 \\
\hline $\begin{array}{l}\text { Bed material } \\
\text { feed position }\end{array}$ & $\mathrm{m}$ & 0.50 & Initial bed mass & $\mathrm{kg}$ & 105 \\
\hline
\end{tabular}

\section{Results and discussion}

Four series of simulations have been performed to investigate the energy flow behaviour in the reactor. The energy flow in the form of heat is analysed varying four main parameters of the reactor which are responsible for the heat transfer. The parameters are bed material circulation rate, bed material temperature, steam flow rate and steam temperature. Energy flow into the reactor in the form of biomass is constant in all cases. The final result of the all energy input to the reactor is product gas from gasification of biomass. This means biomass energy, heat from hot bed material and the heat carried by high temperature steam are 
partially converted into the product gas total energy. The optimization of heat transfer to the reactor is important to get a high amount of energy converted to product gas.

The first series of simulation are run to determine the effect of bed material circulation rate on the energy conversion. This investigation is achieved by gradual increasing the bed material circulation rate while keeping other operating parameters constant. As expected, the total energy contained in the product gas leaving the reactor is increased with the increasing bed material circulation rate. The total energy of the product gas as a function of bed material to biomass ratio is shown in Figure 3. The figure shows the accumulated energy of product gas during 100 s of simulation. This is the case for all simulations performed in this work. The bed material circulation rate is presented as ratio of bed material feed rate to biomass feed rate.

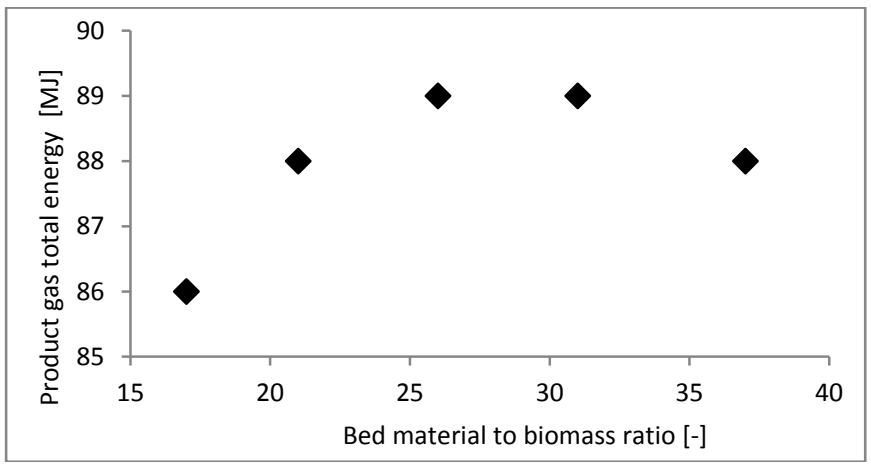

Figure 3: Product gas total energy as function of bed material to biomass ratio.

The product gas total energy reaches its maximum at the bed material to biomass ratio of 26 indicating on the optimum value of the bed material circulation rate about 26 times that of biomass. Above this value there is no reason to increase bed material circulation rate. A slight decrease in product gas energy is observed, indicating that excess bed material circulation can effect negatively in the energy conversion. However the reason for the decrease in total product gas energy is not clearly known and needs further investigation.

Figure 4(a) shows particle temperature distribution across the cross sectional area of the reactor. The char volume fraction distribution along the same cross sectional area is shown in Figure 4(b).

The particle temperature distribution in the Figures $4 \mathrm{a}(1)$ to a(5) corresponds to the bed material to biomass feed ratio of 17 to 37 respectively (see Figure 3 ). The figures show that the particle temperature distribution over the cross sectional area of the reactor is not uniform. Particle temperature is higher close to the hot bed material inlet region whereas lower near to the bed material outlet region. Almost opposite can be seen in the Figures $4 b(1)$ to $b(5)$ representing the char volume fraction. The char volume fraction is lower at the high particle temperature regions whereas the concentration is higher at the low particle temperature region. The lowest char volume fraction distribution is seen 
in Figure $4 \mathrm{~b}(3)$ which indicates the highest fraction of char conversion. The corresponding Figure $4 \mathrm{a}(3)$ shows much more uniform distribution of particle temperature. The Figures corresponds to the bed material to biomass feed ratio of 26 showing the optimum feed rate.

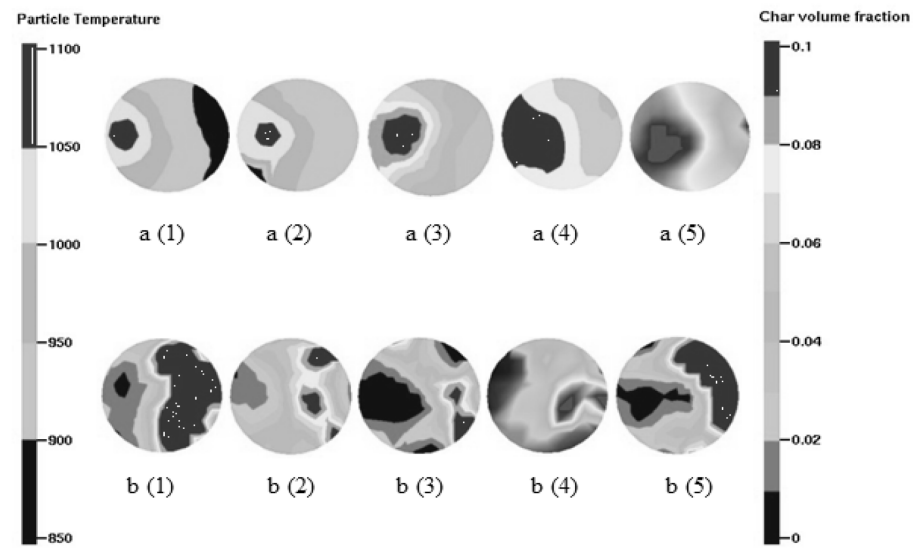

Figure 4: (a) Particle temperature variation along the cross section of the reactor at the height of $0.25 \mathrm{~m}$. (b) Volume fraction of the char particles at the same locations.

The optimum bed material circulation rate is further used for the second series of simulation. The simulations are run to investigate the effect of varying bed material feed temperature into the product gas total energy. Five sets of simulations are performed changing bed material temperature from $1123 \mathrm{~K}$ to $1223 \mathrm{~K}$ with each interval of $25 \mathrm{~K}$. The results are shown in Figure 5.

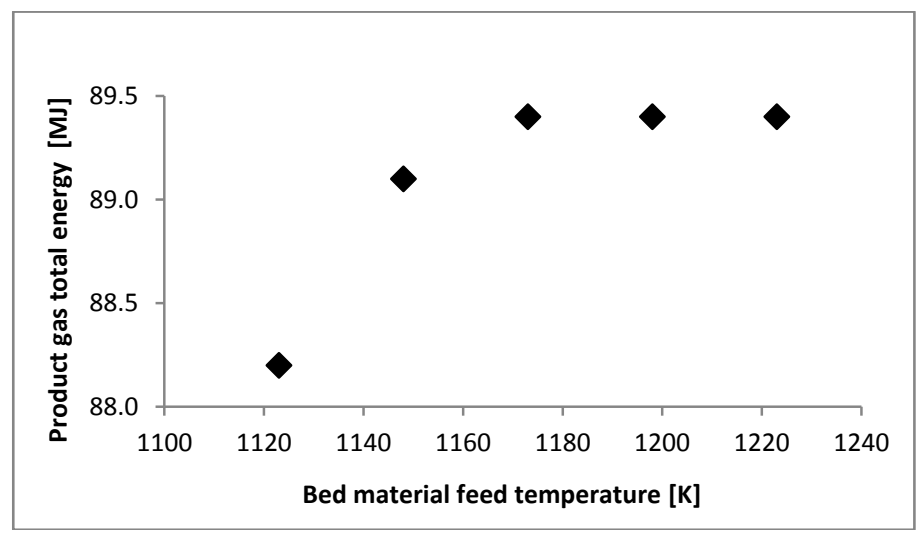

Figure 5: Product gas total energy as a function of bed material feed temperature. 
The product gas energy is increasing with increasing bed material temperature for the first two series of the simulations. The product gas total energy is constant when the temperature reaches $1173 \mathrm{~K}$ and remains unchanged for further increase in temperature. For the given bed material circulation rate, there is no use of increasing the temperature of the bed material.

The third series of simulation are run to investigate the effect of steam flow rate in the performance of the reactor. The optimized bed material flow rate and temperature from the first and second series of simulations are used in these simulations. In the reactor, the bed materials are olivine particles with mean particle size $530 \mu \mathrm{m}$. Approximate minimum fluidization velocity $\left(\mathrm{u}_{\mathrm{mf}}\right)$ in the reactor is $0.18 \mathrm{~m} / \mathrm{s}$. The simulation is performed for the gas velocity of $1.5 \mathrm{u}_{\mathrm{mf}}, 2$ $\mathrm{u}_{\mathrm{mf}}, 2.5 \mathrm{u}_{\mathrm{mf}}, 3 \mathrm{u}_{\mathrm{mf}}, 3.5 \mathrm{u}_{\mathrm{mf}}$ and $4 \mathrm{u}_{\mathrm{mf}}$ which corresponds to each of the steam to biomass ratio from 0.15 to 0.40 . The high temperature steam fed to the reactor through its bottom has two functions. First, it acts as a fluidizing gas. Second, the steam reacts with the other gas and solid components in the reactor to form some of the components of the product gas. The unreacted steam leaves together with the product gas from the top of the reactor. Increase in the steam to biomass ratio increases the steam flow rate as the biomass feed rate is constant. The increase in steam flow rate on the other hand increases energy input to the reactor. Moreover, if there are increasing un-reacted steam, it adds the product gas total energy. Therefore the result of this series of simulation is analysed in the form of change in product gas total energy as a function of steam to biomass ratio which is shown in Figure 6.

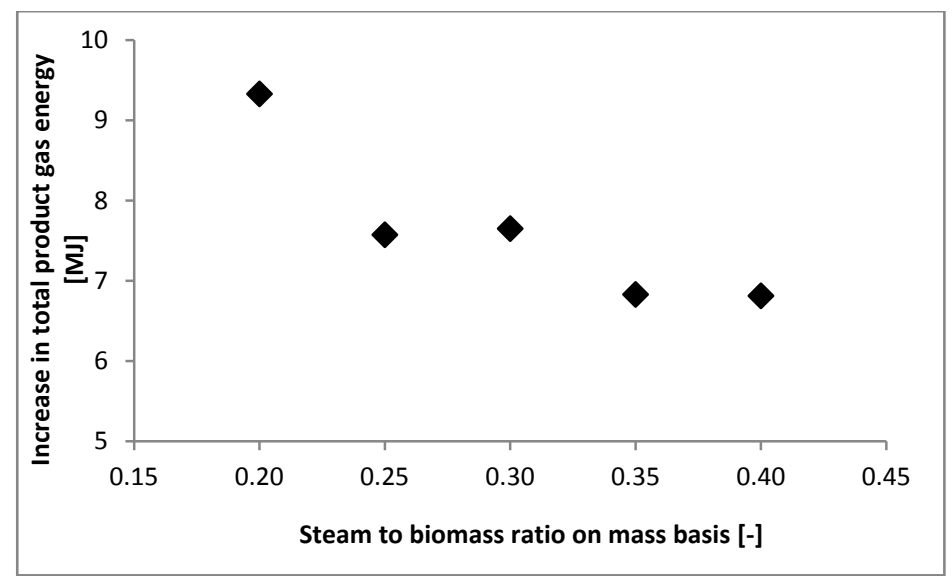

Figure 6: Increase in product gas total energy as a function of steam to biomass ratio.

From the result presented in the figure, the optimum value of the steam to biomass ratio is 0.2 . Increase in steam to biomass ratio does not increase the product gas total energy. The figure also shows that the product gas total energy does not decrease linearly with the increase in steam to biomass ratio. In some 
interval, it is constant. Further investigations are necessary to figure out the reason of this behaviour.

The optimum values of bed material feed rate, bed material temperature and steam feed rate is now used in the fourth series of the simulation to investigate the performance of the reactor with increasing steam feed temperature. The product gas total energy as a function of bottom steam temperature is shown in Figure 7.

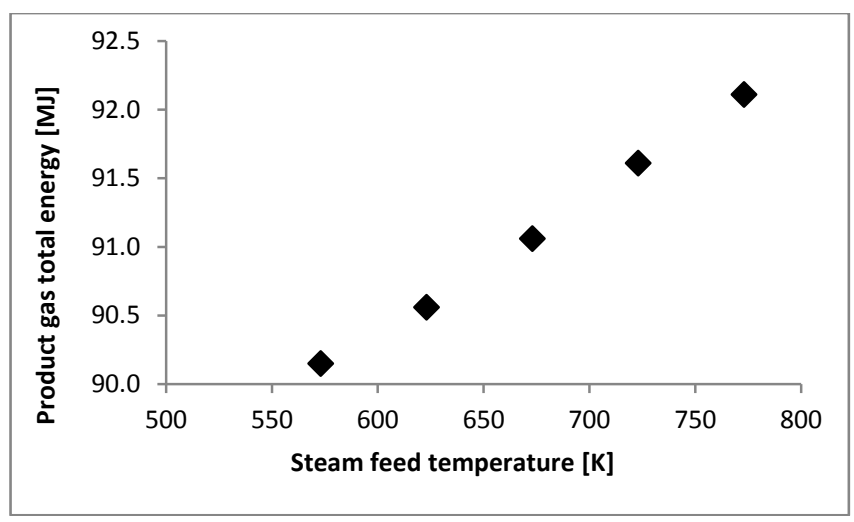

Figure 7: Product gas total energy as a function of steam feed temperature.

The results show that the product gas energy increase almost linearly with the increase in the steam feed temperature.

The temperature distribution of the fluid inside the reactor is shown in Figure 8. The figures represent the half part of the cross section of the reactor which covers dense bed and some freeboard part up to $1 \mathrm{~m}$ height.

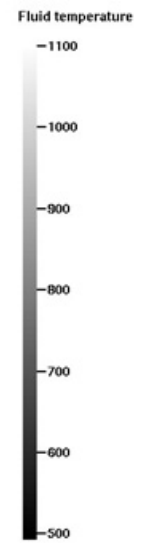

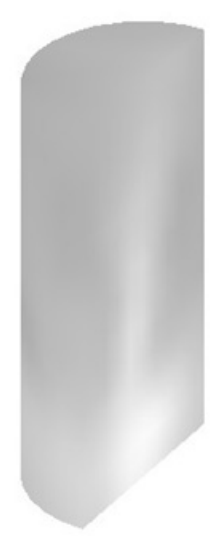

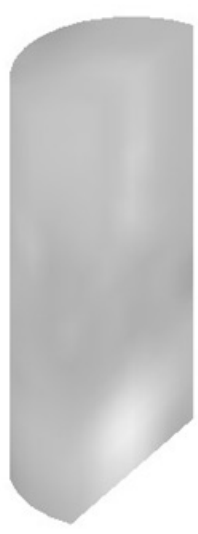

$\mathrm{b}$

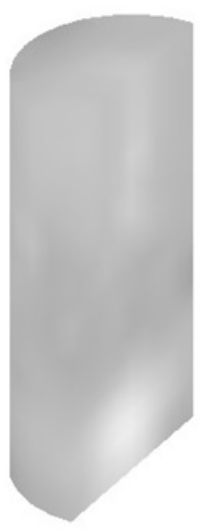

c

Figure 8: Contours of fluid temperature along the height of reactor. 
Figure 8(a) represents the fluid temperature for the first and second series of simulations at bed material to biomass ratio of 26 and bed material temperature of $1173 \mathrm{~K}$. The steam to biomass ratio is 0.20 . Figure $8(\mathrm{~b})$ repeats the conditions of the Figure 8(a) with optimized steam to biomass ratio of 0.2. Figure 8(c) includes the conditions of the Figures 8(a) and 8(b) in additional to increased steam feed temperature of $773 \mathrm{~K}$. The figures show almost uniform fluid temperature in the reactor. However the Figure 8(b) shows most uniform fluid temperature having less spots indicating the area of high temperature concentration.

\section{Conclusions}

Four series of simulations are performed for optimization of heat transfer in the bubbling fluidized bed biomass gasification reactor. The parameters for optimization are bed material feed rate, bed material temperature, bottom steam feed rate and bottom steam feed temperature.

First series of simulation results shows that the bed material circulation rate is optimum when the ratio of bed material to biomass feed is about 26 . Increasing this ratio does not increase the efficiency of the reactor. In the second series of simulations, the result indicates that the optimum temperature for the bed material feed is $1173 \mathrm{~K}$. Increasing the temperature further will not increase the energy conversion rate in the reactor.

The third series of simulation results shows that the optimum steam to biomass ratio is 0.2 . More increase in steam to biomass ratio does not add the product gas total energy.

The fourth series of simulation have been performed to investigate the effect of bottom steam temperature on total product gas energy. The result shows that the energy of the product gas increases linearly with the increase in bottom steam temperature.

\section{References}

[1] Diego, L.F. et al., Modeling of the Devolatilization of Nonspherical Wet Pine Wood Particles in Fluidized beds. Industrial \& Engineering Chemistry Research, 2002. 41: p. 3642-3650.

[2] Demitbas, A., Biomass resource facilities and biomass conversion processing for fuels and chemicals. Energy Conversion and Management, 2001. 42: p. 1357-1378.

[3] Fercher, E., et al. Two Years Experience With The Ficfb-Gasification Process. in 10th European Conference and Technology Exhibition. 1998. Wurzburg.

[4] Hofbauer, H., et al. Six Years Experience With The Ficfb-Gasification Process. in 12th European Conference and Technology Exhibition on Biomass, Energy, Industry and Climate Protection. 2002. Amsterdam. 
[5] Hofbauer, H., R. Rauch, and K. Bosch. Biomass CHP Plant Gussing - A Success Story. in Expert Meeting on Pyrolysis and Gasification of Biomass and Waste. 2002. Strasbourg, France.

[6] Marquard-Mollenstedt, T., et al. NEW APPROACH FOR BIOMASS GASIFICATION TO HYDROGEN. in 2nd World Conference and Technology Exhibition on Biomass for Energy, Industry and Climate Protection. 2004. Rome, Italy.

[7] Snider, D. and S. Banerjee, Heterogeneous gas chemistry in the CPFD Eulerian-Lagrangian numerical scheme (ozone decomposition). Powder Technology, 2010. 199(1): p. 100-106.

[8] Boyalakuntla, D.S., Simulation of Granular and Gas-Solid Flows Using Discrete Element Method, in Department of Mechanical Engineering2003, Carnegie Mellon University. p. 74.

[9] Xie, J., et al., Eulerian-Lagrangian method for three-dimensional simulation of fluidized bed coal gasification. Advanced Powder Technology, 2013. 24(1): p. 382-392.

[10] Xie, J., et al., Simulation on gasification of forestry residues in fluidized beds by Eulerian-Lagrangian approach. Bioresource Technology, 2012. 121(0): p. 36-46.

[11] Umeki, K., et al., High temperature steam-only gasification of woody biomass. Applied Energy, 2010. 87(3): p. 791-798. 